\title{
Application of CFRP Suspenders for Through and Half-through Arch Bridges
}

\author{
Jing Gao', a , Bin Zhao ${ }^{1, b}$ \\ ${ }^{1}$ Civil Engineering, Xiamen University, Xiamen, China \\ agaojing@xmu.edu.cn, bxmu09zb@163.com
}

\begin{abstract}
Keywords: Application, Arch bridge, CFRPs, Suspender
Abstract. Through and half-through arch bridges are modern bridge types due to the development of steel as a building material, in which up to now the dead-load of the deck system and the live load are transferred to the arch rib by steel suspenders. However such suspenders are due to complex mechanical loading patterns and atmospheric attacks suffering fatigue, fretting fatigue, stress corrosion and corrosion. In the past decade, even bridge decks collapsed due to these problems. Realizing the excellent properties of carbon fiber reinforced polymers (CFRPs), including corrosion resistance, very high specific strength and stiffness, and outstanding fatigue behavior, the application of CFRPs for suspenders will be a good choice. In this paper, the bridge deck collapses due to broken steel suspenders will be reviewed, and a proposal for the application of CFRP suspenders for arch bridges will be introduced.
\end{abstract}

\section{Introduction}

Through and half-through arch bridges are modern bridge types due to the development of steel as a building material, in which up to now the dead-load of the deck system and the live load are transferred to the arch rib by steel suspenders. Therefore, suspenders become the most critical load-carrying members. However such suspenders are due to complex mechanical loading patterns and atmospheric attacks suffering fatigue, fretting fatigue, stress corrosion and corrosion. They require a high fatigue and corrosion resistance and have to be easy to install at low cost. Currently, the suspenders are made of steel rods, high-strength steel wires or steel strands. The types of anchorages at either termination directly determine the application feasibility of suspenders in bridge constructions, for which the anchorages play a decisive role in achieving an optimal exploitation of the steel tendons.

Suspenders are suffering due to much more increased corrosion and fatigue loading. The excellent properties of carbon fiber-reinforced polymer (CFRP) has got widely attention, including corrosion resistance, very high specific strength and stiffness, and outstanding fatigue behavior. Empa researchers were developing several anchorage systems for unidirectional CFRP tendons.

\section{The Situation in China Today}

Suspenders are subjected to corrosion, high tensile forces and high stress variations. It has become the key element for the long term reliability and safety in the design of half-through and through arch bridges. In the following sections we will discuss the problems with metallic suspenders.

Corrosion. Corrosion is one of worldwide the most severe challenges for suspenders and stay cables. About twenty years ago the construction of arch bridges with suspenders began in China. And it has grown dramatically since the early 2000s. The corrosion protection of the suspenders in many instances was not sufficient in early stages. Even now designers are still not satisfied with the results that no one can ensure the measures work effective for the long term serve. After only 5 to 10 years of service, corrosion and fatigue problems appeared in a number of cases in the suspenders, which became a potential danger for some bridges.

For certain classes of steel high sustained stresses might also cause the dangerous stress-corrosion, which is difficult to detect.

Fatigue. Suspenders are under both the action of high tensile forces and high stress variations. But designers always paid much attention to the strength requirements and often neglected fatigue. The 
vehicle-induced vibrations, impact, and subsidiary stress resulting from wind, wind-rain, vortex, and galloping oscillations, as described by DIN (2007) in the German recommendation "Design rules for suspenders of through arch bridges", have mostly been ignored in the suspender design. High fatigue resistant components are of great importance for the long term reliability and the safety of the suspender system. To some extent, the durability of a half-through and through arch bridge relies much on the suspender fatigue resistance.

Fretting fatigue. In the region, where the steel wires get first in touch with the grout, there is during the first loading a concentration of the shear stresses at the wire surface. The ASM "Handbook on Fatigue and Fracture" defines wear and fretting fatigue as: "A special wear process that occurs at the contact area between two materials under load and subject to minute relative mo-tion by vibration or some other force." Such fretting fatigue might happen on the load side of sockets grouted with epoxy or even more critical with cement mortar. Due to this high shear stresses there is debonding of the wires from the grout over a length of some few millimeters. Under fatigue loading there will be a relative displacement between the edges of the grout and the wires.

Superimposed bending stress. Generally, there is a special problem on the shortest suspender, which is located near to springing of the arch and has a very short free length. It results in the high bending stiffness. Horizontal relative displacements between the top and bottom ends of the suspenders lead to additional bending moments. With these bending moments superimposed to the normal stresses, there might be a three-dimensional stress state. It is especially dangerous in the case of fatigue. In addition, the temperature variation will also have great effect on the short suspender.

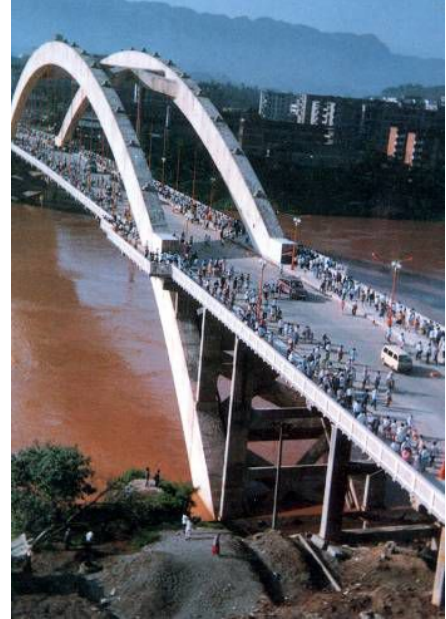

Figure. 1: Xiao-nan-men Bridge Figure. 2: Xiao-nan-men Bridge after the collapse

Case study Xiao-nan-men Bridge. Xiao-nan-men Bridge is a half through reinforced concrete arch bridge with a total length of $387 \mathrm{~m}$, which was built in 1984 and opened to traffic in 1990 . The bridge before the collapse is shown in Fig. 1. In the early morning about 4:00a.m on Nov.7, 2001, the deck of Nan-men Bridge, about $40 \mathrm{~m}$ in the south and $20 \mathrm{~m}$ in the north, was partly collapsed due to several pairs of broken suspenders. Fig. 2 shows the bridge after the collapse.

After the collapse, the bridge site was investigated. Fig. 3 shows the details of the failure suspenders. There were totally four pairs of suspender broke, three pairs in the south and one in the north. The corrosion of the wires was very obvious. Parts of the corrosion protection had been in failure. It was found that all failures of the broken suspenders were in the vicinity of the bottom sockets connected to the deck. Testing of the main arch rib shows that the arch rib was stable, and cracks on the arch rib had no effect on the entire behavior of the rib. Therefore, it was decided to replace all suspenders while the original arch ribs could be utilized. Then it was opened to the public for traffic as normal on June 28th, 2002. 

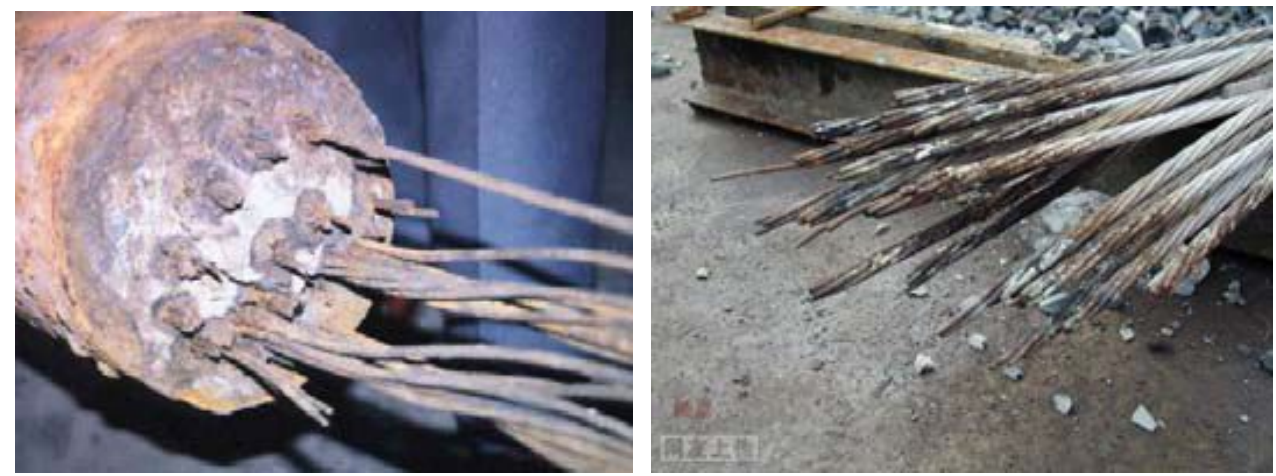

Figure. 3: Details for the broken wires of Xiao-nan-men Bridge

Case study Kong-que-he Bridge. Kong-que-he Bridge (Peacock River Bridge) in Xin-jiang was a half-through concrete filled steel tubular arch bridge with the main span of $150 \mathrm{~m}$ and width of $24.5 \mathrm{~m}$. The rise-to-span ratio of the bridge was $1 / 4.5$. The deck system, consisted of $5.0 \mathrm{~m}$ and $7.5 \mathrm{~m}$ span reinforced concrete T-shaped girder, was suspended below the truss arch rib by 23 pairs of suspender. The bridge was opened to traffic in August, 1998. A part of the deck in Kong-que-he Bridge collapsed and dropped into the river at 5:30a.m on Apr. 12th, 2011. Fig. 4 shows the bridge after the collapse. Because of the deck collapse, the Kong-que-he Bridge was closed to traffic forever. It had been in service for only 13 years, which is very far from its design lifetime.

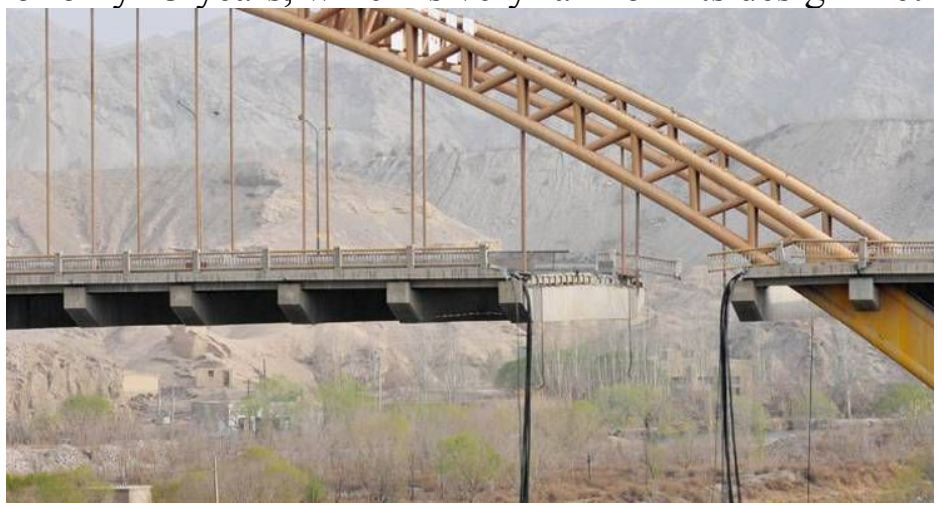

Figure. 4: Kong-que-he Bridge after collapse in 2011

Case study Gong-guan Bridge. Gong-guan Bridge is located in Wu-yi-shan Scenic Area, Fujian, which was open to traffic Nov.20, 1999. It is a half-through reinforced concrete arch bridge with three spans, $80 \mathrm{~m}+100 \mathrm{~m}+80 \mathrm{~m}$. At $8: 50 \mathrm{a} . \mathrm{m}$ on July 14, 2011, when a tourist bus and an overloading truck were passing the bridge, the deck of the first span partly collapsed as a result of broken suspenders. Fig. 5 shows the bridge before and after collapse.

The bus dropped into the river with 22 injured and the driver dead. However, the truck, having self-weight of $20.6 \mathrm{t}$ and carrying $60 \mathrm{t}$ sand, was the direct reason for the collapse, because the nominal carrying capacity of the truck is only 15.65t. The load on the truck was nearly four times of its nominal capacity. The overloading truck may be the obvious reason for the collapse. But the bridge is located in a very important road and had heavy traffic. Many overloading vehicles passed the bridge every day, which resulted in the damage of suspenders to varied degrees.

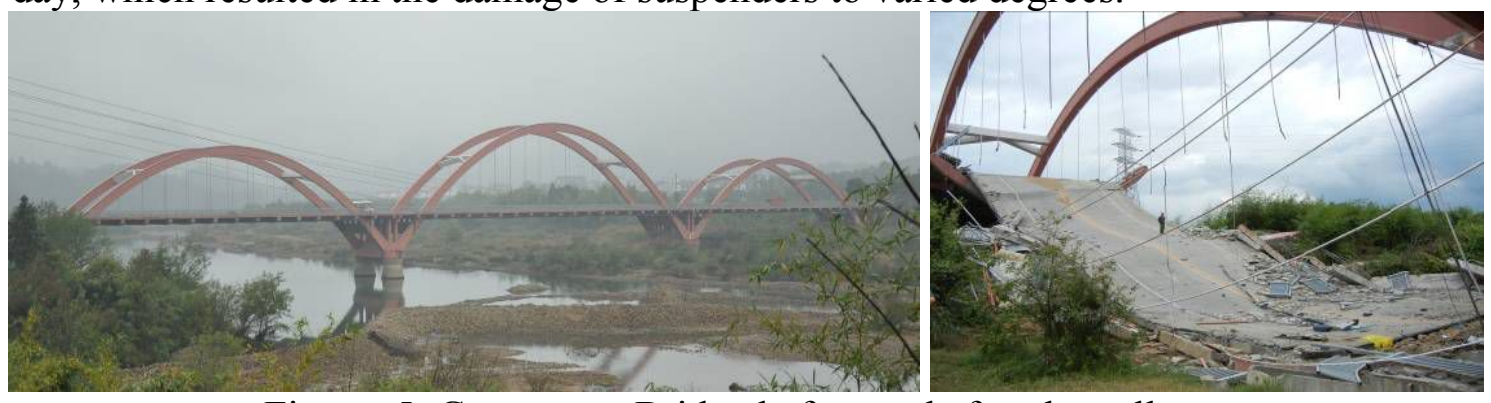

Figure. 5: Gong-guan Bridge before and after the collapse 


\section{Proposal for the Application of CFRP Suspenders}

Fatigue and corrosion related problems are the main reasons for the failures of suspender cables. Corrosion could be avoided with suspenders made of stainless steel or carbon fiber reinforced polymers (CFRP). CFRP is much better on the performance of fatigue than stainless steel. Suffering no stress corrosion, CFRP has been demonstrated the outstanding fatigue which is instrumental for the application for suspenders, in contrast to several stainless steels by EMPA.

EMPA researchers has developed several anchorage systems, which made it possible for the application of CFRP in suspenders or cables. Meier (2012) described the development of a gradient anchorage system for parallel CFRP wire/strand bundles and its application for stays and for post-tensioning cables. The load capacity of this system ranges from $60 \mathrm{KN}$ to $25 \mathrm{MN}$. It has successfully been applied for stay andpost-tensioning cables since seventeen years. Such tendons have been loaded with sustained loads corresponding to stresses higher than $1600 \mathrm{MPa}$. There is a comprehensive monitoring on such tendons and other load carrying CFRP applications in bridge engineering since 1991 de-scribed by Meier, Brönnimann, Anderegg, and Terrasi (2013). All results are very satisfactory

A "pin-loaded CFRP strap system" has been developed at EMPA by Winistörfer (1999) for load capacities up to $3 \mathrm{MN}$, for the gradient anchorage system for parallel CFRP wire/strand bundles is relatively expensive. While this system is very efficient and easy to handle. Originally it was intended for active shear strengthening applications as described by Lees, Winistörfer, and Meier (2002). Since ten years it has been used successfully for the strengthening of historical structures, and most important, for corrosion free, lightweight and fatigue resistant tendons for duty cycle crawlers of the Liebherr Company. This application is, considering the fatigue load spectra, very similar to that of bridge suspenders.

Application for Dongmen Bridge. Dongmen Bridge is a concrete-filled steel arch bridge with a span of $62 \mathrm{~m}$ and a width of $21.8 \mathrm{~m}$. The rise-to-span ratio of the bridge was $1 / 4$. It includes 26 steel cables anchored under the arch ribs and up on 13 horizontal beams. We have applied the computer models to replace the 26 steel suspenders by CFRP cables in numerical method. Then we compared the response of the bridge using CFRP suspenders with the original arch bridge. We used FEM method to analysis the structure, which was modelled in ANSYS simplistically. It is mainly intended for verifying the bridge performance and the feasibility of the replacement. Fig. 6 shows the ANSYS finite element model of Dongmen Bridge.

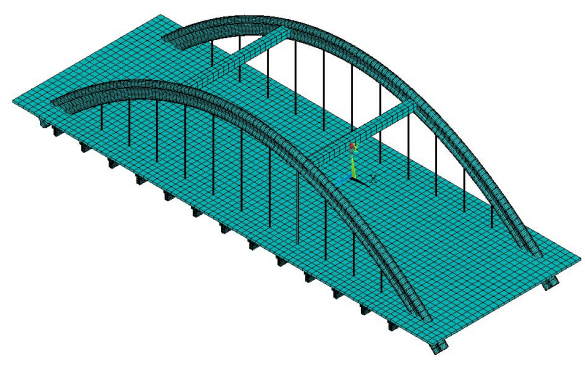

Figure. 6: Finite element model of Dongmen Bridge

Carbon fiber-reinforced polymer wires are produced by mixture of carbon fibers in a reasonable range. The properties of a CFRP wire can simply be calculated based on the rule of mixture, which includes modulus and strength. We used the fiber volume content in the range of $68-72 \%$.In contrast to steel, CFRP has low stiffness and much high strength. Properties of CFRP and steel are shown in Table 1. 
Table 1: Properties of CFRP and steel wires

\begin{tabular}{cccc} 
& CFRP & Steel & \\
\hline Tensile strength & 3,300 & 1090 & {$[\mathrm{MPa}]$} \\
Elastic modulus E & 165 & 195 & {$[\mathrm{GPa}]$} \\
Density & 1560 & 7850 & {$[\mathrm{Kg} / \mathrm{m} 3]$} \\
Fiber content & $68-72$ & $/$ & {$[\mathrm{Vol} \%]$} \\
\hline
\end{tabular}

After calculation, we have given the contrast analysis of the static and dynamic response of the whole bridge before and after the replacement. The vibrational frequency of the bridge changed little. The vibration mode shapes are almost as same as the initial bridge. It proved that the half-through arch bridge of CFRP hangers didn't lead to obvious changes on dynamic behavior. Table 2 shows the frequency of the bridges.

Table 2: The different vibrational frequency of the arch bridge

\begin{tabular}{ccc}
\hline \multirow{2}{*}{ SET } & \multicolumn{2}{c}{ Frequency /Time(s) } \\
& CFRP model & Steel model \\
\hline 1 & 0.7964 & 0.7821 \\
3 & 1.9904 & 1.9615 \\
4 & 2.8736 & 2.9072 \\
5 & 3.6270 & 3.6150 \\
6 & 4.0849 & 4.0286 \\
7 & 4.2789 & 4.2223 \\
8 & 4.3216 & 4.6824 \\
9 & 4.8845 & 4.8359 \\
10 & 5.3920 & 5.8876 \\
\hline
\end{tabular}

We replaced the steel suspenders by CFRP based on the equal strength, which would lead to the decline of the stiffness. Correspondingly, the deflection of the beam attached by suspenders had to increase and the stress distribution of beams might change. We got the deflection of the bridge suffered the full load on the most unfavorable loading location. The distributed load was $42 \mathrm{KN} / \mathrm{m}$ and concentrated load was $1080 \mathrm{KN}$. The result shows that the stiffness of CFRP suspenders is lower and the relevant maximum deflection is just in a rational degree lager than the primal arch bridge with steel hangers. Fig.7 shows the maximum deflection at the bottom of the different suspenders. The results preliminarily prove the application of CFRP suspenders in arch bridges are available and has little effect on the characteristic of the bridge.

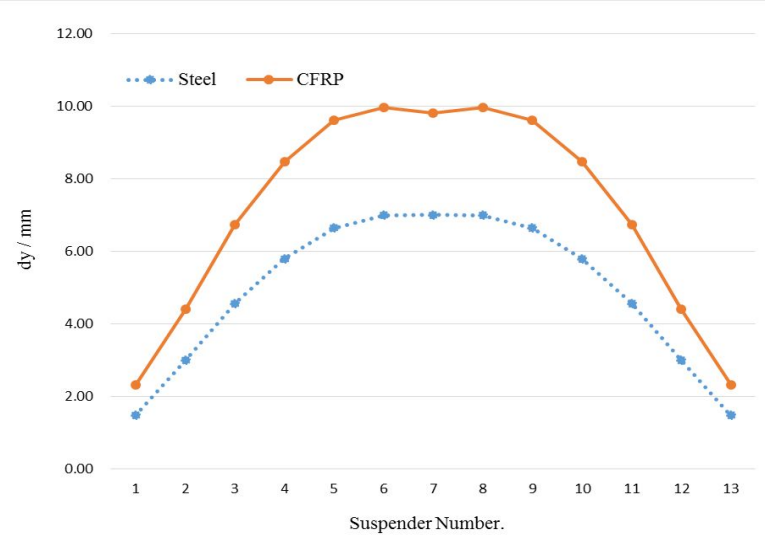

Figure.7: The maximum deflection at the bottom of the different suspenders

Concept and Application of Pin-loaded CFRP Strap System. A carbon fiber non-laminated pin-loaded strap, comprises a number of unidirectional reinforced layers, formed from a single, continuous tape of about $0.12 \mathrm{~mm}$ thickness . The concept which has been patented by Meier and Winistörfer (1998). The two pins could transfer the tensile load from the bridge deck through the 
strap to the arch rib. Compared with the original laminated pin-loaded strap, non-laminated strap has reduced the undesirable stress concentrations and the cost. The non-laminated strap element enables during loading the individual layers to move relative to each other, which allows an equalization of forces in the layers as the strap is tensioned. Control of the initial tensioning process reduces inter-laminar shear stress so that a more uniform strain distribution can be achieved in all layers. In Fig. 8 the left one shows the conceptual design of laminated pin-loaded strap, and the right one is the non-laminated pin-loaded strap.

Suspenders made of pin-loaded CFRP straps can be fabricated with an automatic tape-laying of machine in the Carbo-Link Company or on site. As a flexible element it could easily be connected with a pin to the deck and another pin to the arch rib. The pin-loaded CFRP strap system has been successfully attached to the concrete foundation with pin-loading, which is applied for seismic retrofitting of a masonry post-tensioned wall. The results and the termination are shown in Fig.8.

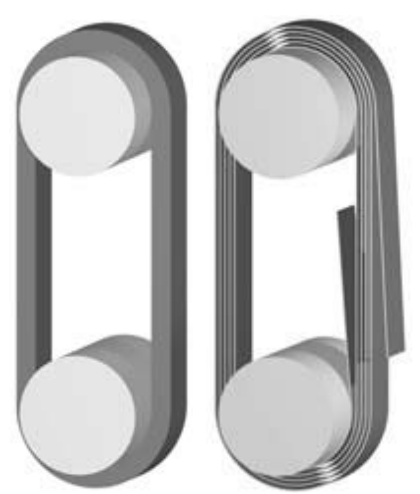

Figure8: Different pin-loaded strap elements
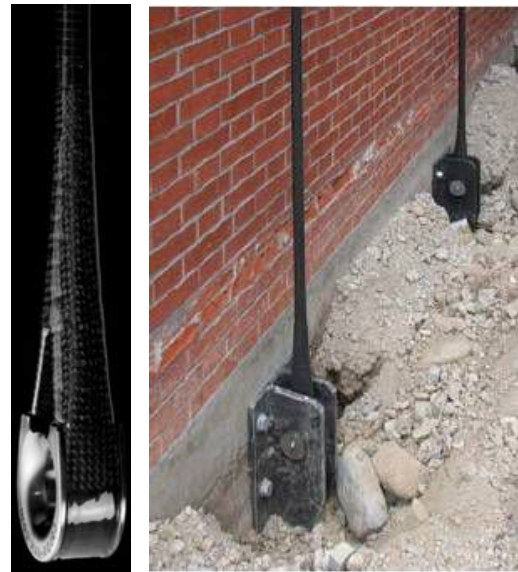

Figure9: Application of pin-loaded straps

\section{Conclusions}

Due to the excellent properties of carbon fibers, including light mass, very high specific strength and stiffness, outstanding fatigue behavior and corrosion resistance, CFRPs have always been one of the most advanced materials in technique. EMPA and BBR Ltd. in Switzerland have been researching CFRP as the cable materials for suspended structures since 1980. In China today, the interaction of the corrosion and fatigue is leading to many failures of suspenders in through and half-through arch bridges with overloading. Application of CFRP suspenders for through and half-through arch bridges has preliminarily been demonstrated the structural feasibility. And the above proposed pin-loaded CFRP strap system for bridge suspenders make it possible and easy for installation. The carbon fibers are wound in a racetrack manner around the pins. It became very difficult to make long-term life cycle predictions, as we have only to rely on the carbon fibers, the pins and not on grouts, polymers or adhesives. However based on the best knowledge available today we can assume that CFRP suspenders will outlast steel suspenders at least three times in the lifetime of service.

\section{Acknowledgements}

The research of this project is supported by the Chinese fundamental research funds for the central universities(granted no. 2013121028)

\section{References}

[1] Andrä W, and Zellner, W. 1969. Zugglieder aus Paralleldrahtbündeln und ihre Verankerung bei hoher Dauerschwellbelastung. Die Bautechnik, 46: Issues 8 and 9.

[2] Andrä, W, and Saul, R. 1974. Versuche mit Bündeln aus parallelen Drähten und Litzen. Die Bautechnik, 51: $289-298,332-340$ and $371-373$. 
[3] Brikenmaier, M, Brandestini, A, and Roš, M.R. 1952. Zur Entwicklung des vorgespannten Betons in der Schweiz. Schweizerische Bauzeitung, 70: 107-114.

[4] DIN. 2007. Leitfaden zum Anhang II-H, Hänger von Stabbogenbrücken des DIN- Fachberichtes 103(Ausgabe 2008).

[5] Evans, UR. 1982. An introduction to Metallic Corrosion.3rd Edition, Edward Arnolds (Publishers) Ltd. and American Society for Metals, 160. 